\title{
O MÚLTIPLO DIALÉTICO COMO MÉTODO DE ANÁLISE DO FENÔMENO JURÍDICO: POR UMA NOVA MATRIZ LATINA DE CRÍTICA AO SENSO COMUM TEÓRICO DOS JURISTAS
}

\begin{abstract}
${ }^{1}$ Aloísio Krohling ${ }^{2}$ Bruno Gadelha Xavier

\section{RESUMO}

A matriz metodológica do Múltiplo Dialético e a Ética como Matriz Rizomática do princípio fontal da vida digna tem como fundamento rizomático os Direitos Humanos em sua perspectiva crítica e afastada dos ditames da economia globalizada, que aprisiona o discurso humanitário em uma lógica neocolonialista. Neste texto realiza-se uma adoção pela crítica jurídica dialética, com fins de, a partir da estipulação da metódica abordada, tecer considerações necessárias, em sede de construção do pensamento crítico-normativo nacional e latino, no intuito de romper com o que Warat denominou de Senso Comum Teórico dos Juristas, a partir do Múltiplo.
\end{abstract}

Palavras-chave: "Múltiplo-dialético, Pensamento crítico latino-americano, "Senso comum teórico dos juristas"

\section{EL "MULTIPLE DIALÉCTICO" COMO MÉTODO DE ANÁLISIS DEL FENÓMENO LEGAL: POR UNA NUEVA MATRIZ LATINA DE CRÍTICA DEL "SENTIDO COMÚN TEORÉTICO DE LOS JURISTAS"}

\section{RESUMEN}

La matriz metodológica de "Múltiple Dialéctico" y "La ética como Matrix rizomática" del principio fontal de la vida digna se basa, de manera rizomatica, los Derechos Humanos en su perspectiva crítica y distante de los dictados de la economía global, que encarcela el discurso humanitario en una lógica neo-colonialista. En este trabajo se lleva a cabo una crítica jurídica dialéctica, para tejer consideraciones necesarias en el pensamiento crítico-normativo nacional y latino, con el fin de romper con lo Warat llama "Teoría del Sentido Común Teorético de Los Juristas".

Palabras-claves: "Múltiple-dialéctico, Pensamiento crítico latino- americano, "Sentido común teórético de los juristas"

\footnotetext{
1 Doutor em Filosofia pelo Instituto Santo Anselmo, Roma. (Itália). Professor da Faculdade de Direito de Vitória - FDV, Espírito Santos. (Brasil). E-mail: krohling@gmail.com

2 Doutorando em Direitos pela Faculdade de Direito de Vitória - FDV, Espírito Santos. (Brasil).Pesquisador da Universidade Federal do Espírito Santo - UFES, Espírito Santos. (Brasil). E-mail: brunogadelhaxavier@ hotmail.com
} 


\section{INTRODUÇÃO}

O atual paradigma do Direito, em sede de análise fenomênica inserida no contexto acadêmico e na práxis cotidiana, encontra-se ancorada em instituições baseadas em uma herança da modernidade, enquanto momento ideológico-institucional, que fixou as matrizes do individualismo, patrimonialismo , dentre outros. Desde a estipulação do esclarecimento moderno, até a fixação do "Sujeito de Direito", individualizado e preso na lógica de reprodução superestrutural que o sustenta, o moderno saber normativo restou preso nos influxos econômicos e calcados na lógica de um sistema capitalista cada vez mais globalizado.

Neste paradigma, a fixação de um novo norte de interpretação do fenômeno regulador em sociedade faz-se necessário ao nosso contexto histórico. Para tanto, parte-se de premissa adotada por Krohling (2014, p.23), no sentido da retomada do discurso da Ética enquanto "Matriz Rizomática" - a partir de uma análise baseada no que denominou-se de "Múltiplo Dialético". O prisma em comento não apenas possibilita a crítica necessária frente o campo jurídico, bem como deve ser considerada uma metodologia de libertação e luta cotidiana para ruptura do "Senso Comum Teórico dos Juristas" (Warat), bem como dos "Direitos Humanos" enquanto discurso apropriado pela economia globalizada e inserida em "pseudo-culturalismos" eurocêntricos.

A busca por um novo método encontra guarida em um prisma de cunho Aristotélico, no sentido de sua Metafísica (obra), de modo que toda a ciência, produção científica, deve possuir um méthodos útil de investigação os princípios os quais são estudados e avaliados, possibilitando um caminho a ser trilhado em prol de atingir um objetivo. Neste contexto, o méthodhos possui como polos a epistemé e a práxis, que, devem ser conjugadas em prol de uma libertação crítica das amarras do conhecimento normativo vigente.

Desta feita, a busca por um novo método de análise e atuação sobre o fenômeno jurídico respeita a busca por uma postura Ética - dentro de uma vertente rizomática - que sustente o caráter humanista e busque uma ruptura com o atual sistema estrutural da economia globalizada, ou seja, uma atuação contrária ao discurso e a prática que mascara e inviabiliza uma militância coletivista.

Assim, buscou-se dividir o artigo em três partes. Na primeira, há a necessidade de se delimitar o método do "Múltiplo Dialético", a partir da matriz teórica elencada (Krohling, 2014), como forma e formulação que busca uma ruptura discursiva e real das amarras pelas quais ainda encontra-se o Direito - enquanto elemento superestrutural e anti-humanista.

Em um segundo momento, busca-se demonstrar como a teoria de Luiz Alberto Warat, qual seja, sua posição no tocante ao "Senso Comum Teórico dos Juristas", mantem-se como realidade deletéria frente o ensino jurídico que reproduz o fenômeno normativo em seu 
núcleo preconceituoso e segregacionista.

A partir desta noção, o terceiro momento defende, a partir da matriz do "Múltiplo Dialético" enquanto defesa da "Ética", a partir de uma matriz rizomática, como forma de defesa do necessário humanismo, a partir da fixação de princípios críticos de defesa e tutela de uma práxis libertadora.

Desta feita, a partir de uma abordagem bibliográfica, com o close readings das obras selecionadas, busca-se uma contribuição ainda pouco debatida na esfera temática em apreço.

\section{0 “MÚLTIPLO DIALÉTICO" ENQUANTO MÉTODO DE LIBERTAÇÃO E CRÍTICA: DO DISCURSO À PRÁXIS}

A partir de um aprofundado estudo teórico e crítico em sede de história do pensamento filosófico, estipulou-se que é imperioso mudar a tradicional nomenclatura de Idealismo e Materialismo e aprofundar as matrizes epistemológicas e as diversas chaves metodológicas do pensamento grego e a sua influência na filosofia ocidental.

Assim, os paradigmas do "Uno" e do "Múltiplo", que são abordados, em sede de pensamento filosófico, desde o problema da unidade ao contexto da multiplicidade, desdobrando-se em discussões atuais, situam-se como duas óticas ou duas chaves teóricas de leitura da filosofia de matriz grega. Subdividiu-se, por uma questão de precisão terminológica, os dois referenciais teóricos em duas variantes: no caso do Uno, em "Uno strictu sensu", em Parmênides, e "Uno ampliado", em Platão, e, no caso do Múltiplo, em "Múltiplo Dialético", "Múltiplo Retórico" e "Múltiplo Erístico-Cético", inserido no discurso e perceptível em inúmeros filósofos - que se diga, desde já, não apenas ligados ao campo jurídico, ou seja, para além dos ditames da "Filosofia do Direito', ou de uma “Teoria da Justiça".

Lembra Krohling (2004, p.96-97), a partir da visão de Maria Cecília de Souza Minayo, que pode-se observar grandes períodos do uso da dialética, em suas vertentes conceituais, a saber:

\footnotetext{
A "dialética antiga", dentro do pensamento grego, chegou a se constituir como um método de busca da verdade pela formulação de perguntas e respostas, para trazer à baila as incongruências e o uso diferenciado entre os pré-socráticos, os clássicos e os sofistas, retóricos e erísticos. Significava a arte do diálogo ou a arte de discutir, mas também a arte de separar, distinguir as coisas em gênero e espécie e classificar as ideias para melhor analisá-las, como desenvolve Platão em Os Sofistas. Anaximandro e Heráclito trazem mais a contribuição da multiplicidade e da mudança. Podemos resumir de um modo geral três concepções de dialética ao longo da história: a) A arte do diálogo usada na lógica formal; b) Uma maneira de dialogar segundo o princípio do caráter contraditório da realidade; c) A própria natureza contraditória do real. (grifo nosso)
} 
Reconhecendo o que Krohling denominou de "Múltiplo Dialético", frente o acima mencionado, deve-se abordar esta metodologia como uma forma de conferir bases para uma dialética dos "Direitos Humanos", em sua vertente de auto e constante crítica.

Desta maneira, a forma de articulação que o presente artigo optou adota uma visão na qual o "Múltiplo Dialético" significa, ou pretende em significar, uma forma de dialética "dinâmica", na qual defende-se uma abordagem de ruptura com o discurso liberal do reconhecimento e respeito unilaterais e pseudo-livres de cunho ideológico, pleiteando, em sede de "Teoria Crítica", uma alternativa que sustente a multiplicidade, diversidade, entre os sujeitos que vá para além das opressões puramente culturalistas - em que pese respeitá-las em prol da uma observância de uma mesma exclusão em comum, causada pelo espeque da economia globalizada.

Com a consequente crítica da própria figura de um "Sujeito de Direito", baseado em leituras neokantianas que insistem por vincular sujeito e propriedade em uma lógica universalista, a lógica do "Múltiplo Dialético" remonta a noção da própria contradição do real, na qual as vertentes liberais burguesas sobre o fenômeno normativo não passam de prismas voltados para manutenção das desigualdades e excessiva culturalização de problemas de cunho global.

A libertação da barbárie causada pela logicidade do discurso normativo é, assim, própria das sociedades latinas que ainda lutam por sua autonomia epistemológica e social. A visão de uma alteridade somente deve ser defendida como possibilidade se acompanhada de uma crítica às estruturas que mantém a desigualdade em sede de sistema econômico vigente, propagando a constante negação dos sujeitos plurais frente as discrepâncias materiais e simbólicas cotidianas, em um sistema no qual a luta diária por "Direitos Humanos" deve ser encarada, em primeira instância, como crítica ao que se deve lutar, ou seja, uma volta ao movimento reflexivo antes de alterar a práxis em si, contemplando a visão freireana na qual o conhecimento não é algo caracterizado por uma vertente dogmático-progmática, mas sim um contínuo e dialógico processo de fazer-se a si próprio (FREIRE, 1978, p.12 e ss.).

O modelo de uma expressão "Múltipla Dialética" é, assim, uma tutela da crítica enquanto elaboração reflexivo-instrumental que supera as teorias tradicionais do corpo jurídico, em especial as que são frutos da reflexão liberal que sustenta a forma jurídica enquanto simbiose da forma mercantil - até os dias atuais, com o paradigma de um “capitalismo desorganizado" cada vez mais apropriador:

Por um lado, o capitalismo parece mais organizado do que nunca: além de dominar todos os aspectos da vida social, neutralizou seus inimigos tradicionais (o movimento socialista, o ativismo operário, as relações sociais não mercantilizadas, etc). Por outro lado, as formas de organizações que começar a surgir ainda são opacas e provisórias, e as instituições, tornadas obsoletas, necessitam ser repensadas, 
aumentando a sensação de desorganização. [...] No campo da regulação, o princípio do mercado adquiriu pujança sem precedentes. Tendo extravasado a economia, o princípio do mercado, impulsionado pela ideologia neoliberal, coloniza e domina o princípio do Estado e o princípio da comunidade de modo muito mais intenso [...] (ARANHA, 2011, p.59).

Por conseguinte, a crítica do "Múltiplo Dialético", aqui apropriada na visão de Krohling, também faz parte de um processo histórico e contínuo de descolonização do pensamento eurocêntrico - acima mencionado - com a defesa do subalterno, do periférico e marginalizado campo crítico latino-americano, como uma ferramenta transgressora e transformadora do seio social: a crítica como prática de libertação. Pontua Wolkmer (2014, p.248):

\begin{abstract}
A crítica como saber e como prática de libertação deve demonstrar até que ponto os indivíduos estão codificados e moldados pelos determinismos históricos, que nem sempre estão cientes das implicações hegemônicas das dissimulações opressoras, das falácias ilusórias do mundo objetivo real. O pensamento crítico tem a função de provocar algo na consciência dos sujeitos sociais oprimidos, que sofrem as injustiças por parte dos setores dominantes, dos grupos privilegiados e das formas institucionalizadas de violência e poder, tanto do poder global quanto do poder local. Naturalmente que a crítica como dimensão política e epistemológica tem papel conscientizador altamente positivo à medida que se torna o instrumental operante adequado ao esclarecimento, à resistência e à liberação, indo ao encontro dos anseios societários, e respondendo aos interesses e as necessidades de todos aqueles que sofrem qualquer forma de discriminação, exploração e exclusão.
\end{abstract}

Assim, o "múltiplo", aqui defendido, coaduna com uma visão de desconolização e constante crítica frente o pensamento e a racionalidade que insistem por macular a esfera jurídica contemporânea. Há a demanda pelo reconhecimento da "negatividade do mundo da vida" - não confundida com o sentido Hegeliano ou Pós-Hegeliano do termo -, como indica Dussel (2001, p.58), que aduz a necessidade de se romper com este fator determinante para que a atual ordem política vigente não mais destrone a reprodução e a participação democrática dos sujeitos alvos do processo de exclusão econômica global. A transgressão da hegemonia é, neste diapasão, atitude diária:

Em suma, uma episteme crítica da política deve transgredir as fronteiras do que é hegemônico, assumindo compromisso com a prática política do "outro", contribuindo para implementar estruturas políticas justas e legítimas, mediante novas normas, leis, ações e instituições políticas. [...] diante dos grandes paradigmas essencialistas e universalistas da tradição ocidental, como ser, conhecer, saber e comunicar, apresentam-se, na transposição da totalidade excludente e na dimensão agora da exterioridade libertadora, elementos críticos e descolonizadores de um projeto político centrado no outro, base para repensar o Direito e o pluralismo jurídico (WOLKMER, 2014, p.249-250).

A descolonização e ruptura com o discurso liberal vigente dentro do corpo normativo, em prol de uma visão humanística e crítica dos fenômenos sociais e da regulação diária, é 
uma atividade que pressupõe um diagnóstico das ideologias que comprometem uma luta global contra o sistema econômico que oprime, com a conhecida eficiência neoliberal, Direitos Humanos fundamentais em seu sentido libertador. Passa-se, assim, para uma discussão sobre o sequestro epistemológico feito pelo denominado "Senso Comum Teórico dos Juristas", a partir das formulações de Luiz Alberto Warat.

\title{
3 A NECESSÁRIA RUPTURA COM O “SENSO COMUM TEÓRICO DOS JURISTAS” E A DEFESA DA “CARNAVALIZAÇÃO”: REFLEXÕES NO RASTRO DE UM TEÓRICO INSERIDO NA "ESTRADA EPISTEMOLÓGICA" "ARGENTINA-BRASIL"
}

A partir da reflexão supradelineada, na qual defendeu-se o método do "Múltiplo Dialético" enquanto um caminho plural e não vinculado ao atual comprometimento encilhado da teoria jurídica, menciona-se a visão de Luiz Alberto Warat, jusfilósofo argentino que desenvolveu parte de sua teoria no Brasil, como uma forma de complementação epistemológica de uma práxis libertadora. Em especial seu discurso sobre o "Senso Comum Teórico Dos Juristas", a seguir delimitado, no qual percebe -se que a denúncia acima retratada, de um Direito comprometido com verdades de um capital hegemônico, faz parte de uma gama de argumentações inseridas em uma posição de potestade, um “Monastério dos Sábios”. É visível o cuidado que Warat (1983, p.123) possui quando, em sua obra “A pureza do poder”, disserta sobre a relevância do saber jurídico no contexto de representações de controle social, a saber:

\begin{abstract}
O saber jurídico, enquanto ciência social, deve ser visto como um sistema de articulações tópicas, construídas a partir de problemas e endereçados à produção de argumentos para a paralisacão de conflitos sociais. Assim. os discursos da Dogmática Jurídica encontram-se comprometidos com certos efeitos de verossimilhança e não com questões vinculadas à problemática da verdade. Uma teoria que tenha por objeto temático as relações entre as normas jurídicas e os enunciados da Dogmática Jurídica não deve, portanto, preocupar-se com o estabelecimento das condições de verdade (nem das proposições jurídicas, nem das normas), mas sim com as funções sociais que surgem a partir deste tipo de relações. O conhecimento jurídico deve ser visto mais como uma técnica de efeitos do que como uma ciência de fatos.
\end{abstract}

Faz-se necessário apresentar um conceito de extrema importância na desconstrução do moderno saber jurídico: "senso comum teórico dos juristas" (Warat). Esta terminologia traz a ideia da presença de condições implícitas de produção, circulação e consumo de verdades nas múltiplas práticas do Direito, um neologismo em busca da dimensão ideológica das verdades jurídicas.

Com a influência nas práticas cotidianas de uma constelação de representações, préconceitos, imagens, hábitos de censuras enunciativas, ficções, estereótipos, metáforas e 
normas éticas, pauta-se anonimamente os atos de decisão e enunciação. Convenções linguísticas instan-made, prontas para serem enunciadas espontaneamente, derivadas em fetiches, visões, ideias dispersas e lembranças que regulam o discurso.

Um arsenal de pequenas condenações de saber, linguisticamente constituídas em uma perspectiva eletrificada e invisível no interior da linguagem jurídica, vagando a serviço das relações de poder (WARAT, 1994, p.13-15). Algo que não deixa de ser uma significação extra-conceitual inserida em um sistema de conceitos, um casulo ideológico dentro da ciência, uma dóxa no interior de uma episteme.

Empregam-se estrategicamente conceitos na prática jurídica, utilizando os resultados do trabalho epistemológico como uma nova instância da dóxa - algo que permite ver o valor político dos processos de objetivação. A partir deste retorno da episteme a dóxa, vislumbra-se o caráter ideológico do discurso epistemológico, um discurso transmutado em elemento mediador, resultantes da instrumentalização da episteme em consequente dóxa (WARAT, 2004, p.30-31).

Este lugar secreto expõe um emaranhado de costumes intelectuais, verdades, ocultando o componente político de investigação, tornando sacral certas imagens e crenças, vistas na soberania do discurso prático e acadêmico que reproduz esta ilusão epistêmica, escondendo o fato da impossibilidade de eliminação do campo ideológico nas discussões sobre verdade (WARAT, 1994, p.14-18).

Desta feita, pode-se afirmar que a perspectiva de Luiz Alberto Warat pode ser considerada, devido a seus influxos pós-estruturais, esta nova categoria de contribuição acadêmica e social proposta. Ora, em termos de percepção acerca da realidade na condição moderna, Warat elucidou que a produção das verdades no campo jurídico foi uma grande epopeia que produziu um modo específico de interpessoais relações, de sociedade e cultura.

O substrato desta lógica vislumbra uma pluralidade heterogênica de sintomáticas, fantasias e identificações próprias a uma lógica empresarial da razão como um elemento que possuía o destino de resolver a tensão entre o caos e a ordem a fim de iludir a espécie homo sapiens que poderia viver fora da multiplicidade existencial. Esta razão fabril que produziu uma ordem que pôs fim as ambivalências, utilizando seu poder de império frente seus elementos essenciais: a claridade, a certeza, a transparência e o unívoco.

Obviamente, o fator da ambivalência da condição construtiva histórica não foi levado em consideração, resta-se olvidada a produção de diferenças que nos constitui neste paradigma: a guerra moderna contra o caos produziu uma infinidade de conflitos interpretativos em busca de guerrilhas unívocas epistemológicas, que estabelecem amarras da razão na captura do desejo (WARAT, 2004, p.16).

O saber científico acaba por se inscrever na sociedade como um dispositivo de poder, 
que, por ser significado, também pode ser manifestado como silêncio, vigilância e unidade. As significações, assim, podem aparecer como disciplina corporal ou regularização axiomática, moralizando hábitos cotidianos, os fetichizando (WARAT, 1995, p.347).

Neste ponto, a teoria waratiana da "carvanalização do saber" acerta, com precisão, um conjunto de representações nas quais pode-se propor uma metodologia de aprendizagem e desconstrução - logo, ética - no sentido de romper com a preocupação colocada no primeiro capítulo do presente. Em outras palavras, o "Carnaval Epistemológico", a seguir desenvolvido, coaduna com uma visão "Múltipla Dialética".

Pois bem, o autor reconhecia que aprender era a mais bela oportunidade de se reencontrar consigo mesmo, tendo como ponto de partida as situacionais experiências que a própria vida proporciona; uma beleza do constante inesperado - adiciona-se, um espanto quase semelhante aos primeiros momentos de leitura de um diálogo platônico, uma sensação de estranheza positiva - que leva até o gozo do saber, uma arte que não abandona sua faceta estética (WARAT, 2004, p.99).

Exsurge, neste diapasão, a proposta waratiana de uma epistemologia surrealista e carnavalesca, respeitando sua tese em "Manifesto pelo surrealismo jurídico" (WARAT, 2004, p.187 e ss.). Carnavalizar é por em crise a verdade, suprimindo em sua inversão o corte feito pela episteme. A ciência deve ser uma literatura que mantenha o sentido suspenso, com uma linguagem provocadora de respostas sem as conferir (WARAT, 2004, p.108). Disserta o jusfilósofo $(2004$, p.144) sobre a necessidade desta atitude o que segue:

\begin{abstract}
Eu apelo à carnavalização para conhecer a cultura, a democracia e o Direito como ações, como verbo, e não como substantivo. O Direito, a cultura e a democracia precisam ser vividos permanentemente como territórios de conquista e não como resultados. Os resultados são as formas legíveis desse trinômio. São as formas pelas quais eles ficam enclausurados pelas máscaras de um poder que vê subversão nas emergências do diverso e do novo. [..] Teima-se, na carnavalização, em menosprezar as evidências estabelecidas, a repressão burocrática e o livre jogo dos egoísmos. [...] A democracia tradicionalmente vinculada ao Direito - nos estreitos limites da versão liberal do mundo - termina sendo apresentada como a concretização histórica de um "Estado Democrático" que se assegura como tal através dos mecanismos instituintes do "Estado de Direito". Essa expressão conota principalmente a necessidade de fazer reinar a lei, de fazer do cumprimento das leis a mola propulsora da democracia. Dessa maneira, na concepção jurídico-liberal da democracia, a ordem política fica reduzida à administração legal do poder do Estado. Contrariamente, a versão carnavalizada da democracia se abrirá para o espaço de criação do Direito. Enquanto a concepção jurídico-liberal da democracia mostra os Direitos instituídos, a carnavalização inventa, ou melhor, mostra a possibilidade de inventá-los permanentemente.
\end{abstract}

Sendo o carnaval um espetáculo que não possui passarela, não há uma separação entre atores e espectadores, todos participam e convergem ao ato. Não verifica-se a exatidão na festividade, não sendo ensinado, entretanto, vivido imaginariamente na pluralidade de 
fantasias. De acordo com esta postura, o conceito de teoria presente no imaginário científico é diametralmente oposto ao ato carnavalesco, de modo que, sem uma significação que promova a participação - de um indivíduo que não deve viver isolado, muito menos de alguém que possua excesso de vínculo com um outro, ambos alienados (WARAT, 2004, p.351 e ss.) -, não existem operações que desmistifiquem o "senso comum teórico", muito menos uma apropriação crítica de eventos classificados como injustos (WARAT, 2004, p.109). Mais uma vez é necessário menção ao texto do autor (2004, p.145):

\begin{abstract}
A metáfora do carnaval pode ajudar a entender que não há mais uma autoridade incontestável, fiadora do poder e do saber; ou se você prefere, na democracia não se pode mais aceitar o princípio de um suposto possuidor do sentido da lei, do sentido último do poder e do conhecimento social. De alguma maneira estamos diante de um princípio de politização do social que é baseado no dilema, no conflito e no debate na sociedade. O problema é tentar estabelece-lo, preservá-lo e logo ampliá-lo. Não se poderia tentar a implementação de tal princípio sem pressupor que o saber e o poder não são mais apropriáveis por alguém. Eles se tornam, em certo sentido, práticas vazias. [...] O lugar vazio seria, enfim, um lugar simbólico, onde o conflito permitiria o devir do novo e a ocupação temporária dos espaços de autoridade. Ninguém possuiria autoridade como qualidade, nem poderia situar-se como locador permanente. Todos os que porventura viessem a ocupar ditos lugares estariam em trânsito, exercitando-os. O lugar vazio poderia também ser visto como a arte de inventar novos espaços. O lugar vazio seria, no fundo, um lugar carnavalizado.
\end{abstract}

Complementa-se a brilhante ideia do autor, que por meio do amor, da magia, da loucura, da poesia e dos desvios possibilitados pelo inconsciente e atravessados pelo desejo buscava maneiras de conhecer que trouxessem um romper com a racionalidade instrumental pura da modernidade (ROCHA, COSTA, 2013, p.289).

A "carnavalização" é, assim, uma forma de crítica constante do "Senso Comum Teórico dos Juristas", rompendo com a existência de um "Monastério dos Sábios" que insiste por sequestrar o discurso jurídico nos valores da economia global, do eurocentrismo desmedido e das relações de poder que tornam invisíveis os oprimidos sociais. É, portanto, uma atitude múltipla, uma atitude dialética.

Ponto seguinte, é de bom alvitre apontar a defesa pela "Ética Rizomática" enquanto representação teórica e prática que embasa as práticas acima mencionadas.

\title{
4 BASES PARA UMA ÉTICA CONTEMPORÂNEA: O RIZOMA ENQUANTO FIGURA DE LIBERTAÇÃo
}

Uma vez fixada atitudes de defesa em prol de um pensamento crítico latinoamericano, pelo reconhecimento da multiplicidade e da necessidade de ruptura didática e prática com um "senso comum teórico", parte-se para a discussão da matriz ética que embasa este posicionamento.

Ora, as relações culturais construídas e sustentadas na história social estão atreladas 
ao desenvolvimento das relações de produção e reprodução do sistema econômico e político, logo, o sustentar de uma "Ética Rizomática" (Krohling) é, em primeira vertente, a necessidade de ruptura com um sistema de circulações axiomáticas que reforça o caráter superestrutural, segregacionista é deletério da ética do sistema econômico contemporâneo, que insiste por adentrar e sustentar a forma jurídica enquanto simbiose da forma mercantil. Complementa Krohling (2014, p.29):

Ética é, segundo Aristóteles, a "morada do ser", que interpretamos como a construção do caráter da pessoa humana na busca da felicidade e do bem viver ou da vida digna de todos os seres viventes, através da alteridade e responsabilidade e da sensibilidade alteral. Essa busca vai se afirmando com o surgimento da consciência crítica em relação à cosmicidade da realidade natural circundante e à corporeidade do ser humano, no desenvolvimento e crescimento da liberdade, da autonomia e da autorealização da personalidade em sua dimensão pessoal, bem como nas relações de solidariedade, de justiça, de respeito, reciprocidade e responsabilidade com os outros seres humanos, todos os animais e toda a natureza. Não existe ética sem alteridade e sem responsabilidade.

Pois bem, a ética deve ser considerada, neste trabalho, como a filosofia ou crítica da moral, colocando-se também como "filosofia segunda", pois está no nível da práxis humana. A ética da vida digna - incluindo o cosmos ou a natureza, os animais e o homem - como matriz rizomática - in casu, rizoma enquanto significante que remonta ao substantivo raiz - da dignidade da pessoa humana, e vida digna de todos os seres vivos, deve ser enquadrada como uma formulação crítica que rompa com o discurso liberal dos direitos humanos, tendo por metódica o "Múltiplo Dialético".

Ou seja, por matriz rizomática compreende-se a fonte matricial e originária do princípio fontal da vida digna de todos os seres viventes, e não só da pessoa humana. Em vez de uma visão antropocêntrica, própria de discursos ultrapassados, defende-se uma perspectiva mais ampla, a cosmocêntrica, incluindo toda a cosmicidade, a natureza e os animais (KROHLING, 2014, p.28-30).

Isto porque, a partir da leitura do primeiro volume de "Mil Platôs" (Deleuze, Guatarri, 1995, p.12-20), é perceptível que na natureza as raízes são pivotantes com ramificação deveras mais numerosa, lateral e circular, não dicotomicamente estabelecidas, a saber (estabelecidos na obra citada a partir de proposições em forma de parágrafos):

Princípios de conexão e de heterogeneidade: qualquer ponto de um rizoma poder conectado a qualquer outro e deve sê-lo. [...] Princípio da multiplicidade: é somente quando o múltiplo é efetivamente tratado como substantivo, multiplicidade, que ele não tem mais nenhuma relação com o uno como sujeito ou como objeto, como realidade natural ou espiritual, como imagem e mundo. As multiplicidades são rizomáticas e denunciam as pseudomultiplicidades arborescentes. [...] Princípio da ruptura a-significante: contra os cortes demasiado significantes que separaram as estruturas, ou que atravessam uma estrutura. Um rizoma pode ser rompido, quebrado em um lugar qualquer, e também retoma segundo uma ou outra de suas linhas e 
segundo outras linhas. [...] Princípio da cartografia e decalcomania: um rizoma não pode ser justificado por nenhum modelo estrutural ou gerativo.

A leitura dos conceitos-chave da ética da vida digna, da matriz rizomática, e de uma crítica ao discurso usual da "dignidade da pessoa humana" em rede com todos os seres viventes, são atitudes próprias de uma reflexão que se proponha a colocar-se em uma posição de descolonização intercultural frente a reflexão liberal-burguesa.

Neste contexto, o prisma rizomático pressupõe a existência de uma tessitura imbricada na qual, em termos de raciocínio e determinação complexos em sociedade pósindustrial neocapitalista, há o sustentáculo de certos axiomas - aqui veiculados como raízes no sentido Deleuziano - como formulação crítica e assecuratória de uma ética pautada na ruptura com os axiomas liberais vigentes. Em equiparação aos rizomas da botânica, a ética que compartilha desta matriz proposta liga-se, de maneira covalente, ao princípio fontal da dignidade humana, conforme já proposto, estando conectada a outros princípios rizomáticos.

Propõe-se, neste contexto, como princípios rizomáticos ligados à matriz fontal estabelecida, os seguintes: Vida; Cosmicidade; Corporiedade; Alteridade; Consciência Crítica; Justiça; Igualdade e Liberdade. Todos estes fundamentos, críticos e estabelecidos em uma lógica de possibilidade de justificação de uma leitura crítica dos "Direitos Humanos", devem ser observados a partir de um discurso de constante ruptura com a apropriação que o sistema estrutural-estruturante do capitalismo atual propaga.

Outrossim, deve-se afirmar que o rol mencionado acima não é exaustivo, apenas exemplifica a multiplicidade de visões e de rizomas inseridos no seio social e no contexto protetivo pelo qual deve-se pautar o discurso humanista e social.

Assim, a "Ética Rizomática" como forma de pauta axiomática somente encontrará guarida na leitura proposta se encontrar-se de maneira a romper com o discurso liberal vigente na contemporaneidade, sendo cada um de seus rizomas lidos não pela vertente presente na retórica material, qual seja, dos valores do sistema econômico atual, mas sim na crítica ao último. Neste contexto, as atitudes de ruptura com o "Senso Comum Teórico", como as de Warat, são múltiplas, dialéticas e éticas.

\section{CONSIDERAÇÕES FINAIS}

Levando em consideração a necessidade de ruptura com um discurso cada vez mais deletério em relação aos "Direitos Humanos", o conhecimento crítico desde a América Latina é de relevância essencial em um contexto de ruptura epistemológica e prática com os axiomas do sistema de reprodução político-econômico vigente.

Neste sentido, buscou-se, no presente escrito, delimitar, em uma primeira vertente, a 
necessidade de adotar-se um método como o do "Múltiplo Dialético", como forma de sustentar a investigação em prol da multiplicidade de um ser social inserido nas contradições do real e ameaçado pela unicidade do pensamento normativo liberal-burguês.

Posto a dialética em sua multiplicidade como forma de observância do fenômeno social-normativo, partiu-se, a partir de uma perspectiva waratiana, na defesa pela ruptura do "Senso Comum Teórico dos Juristas", como forma de romper com o moderno saber jurídico que, superestruturalmente, inviabiliza as lutas sociais e mantém o status quo das desigualdades contemporâneas.

Neste contexto, a "carnavalização" epistemológica e do ensino torna-se uma proposta real de alternância do discurso e da práxis, abrindo as portas para a percepção da pauta ética proposta no último item do presente escrito, qual seja, uma "Ética Rizomática".

Por sua vez, compreende-se como a ética baseada na leitura Deleuziana de rizoma um porto de ruptura com as pré-concepções de uma teoria jurídica presa nos ditames de uma modernidade eurocêntrica. A fim de romper com a lógica de reprodução do capital em sua faceta jurídica, a lógica do rizoma sustenta uma leitura crítica de todo o sistema normativo a partir da percepção de uma tessitura pulsante no seio social.

De certo, a reflexão é apenas o início de uma discussão muito maior, entretanto, uma manobra inicial frente um complexo caleidoscópio conceitual e com a demanda de uma práxis libertadora.

\section{REFERÊNCIAS}

ARANHA, Guilherme Arruda. Introdução crítica ao Direito: em busca do equilíbrio entre regulação e emancipação. São Paulo: Paulus, 2011.

DELEUZE, Gilles; GUATTARI, Félix. Mil Platôs: capitalismo e esquizofrenia . Vol.1. Rio de Janeiro: Edições 34, 1995.

DUSSEL, Enrique. Hacia uma filosofia política crítica. Bilbao: Brouwer, 2001.

FREIRE, Paulo. Pedagogia do oprimido. Rio de Janeiro: Paz e Terra, 1978.

KROHLING, Aloísio. Dialética e Direitos Humanos: Múltiplo Dialético - Da Grécia à Contemporaneidade. Curitiba: Juruá, 2014. 
ROCHA, Leonel Severo; COSTA, Bárbara Silva. Ensino do Direito e percepções discentes: contribuições waratianas para a construção da pedagogia do novo. In: SILVEIRA, Vladmir Oliveira da; SANCHES, Samyra Haydêe Dal Farra Naspolini; COUTO, Mônica Bonetti. Educação jurídica. São Paulo: Saraiva, 2013.

WARAT, Luiz Alberto. Introdução ao estudo do Direito: interpretação da lei, temas para uma reformulação. Vol.I. Porto Alegre: Sergio Antonio Fabris, 1994.

A pureza do poder. Florianópolis: Editora da UFSC, 1983.

Saber crítico e senso comum teórico dos juristas. In:

Direito: o sonho acabou. Vol.2. Florianópolis: Fundação Boiteux, 2004.

Epistemologia do

Direito: o sonho acabou. Vol.2. Florianópolis: Fundaça Boiteux, 2004.

La forntune du pot. In: WARAT, Luiz Alberto. Epistemologia do Direito: o sonho acabou. Vol.2. Florianópolis: Fundação Boiteux, 2004.

. Utopias, conceitos e cumplicidades na interpretação da lei. In: WARAT, Luiz Alberto. Epistemologia do Direito: o sonho acabou. Vol.2. Florianópolis: Fundação Boiteux, 2004.

Manifestos para uma ecologia do desejo. In: WARAT, Luiz Alberto. Territórios desconhecidos: a procura surrealista pelos lugares do abandono do sentido e da reconstrução da subjetividade. Vol.1. Florianópolis: Fundação Boiteux, 2004.

. Confissões e ilusões: manifesto para contradogmáticas. In: WARAT, Luiz Alberto. Epistemologia do Direito: o sonho acabou. Vol.2. Florianópolis: Fundação Boiteux, 2004.

.Introdução ao estudo do Direito: a epistemologia jurídica da modernidade. Vol.II. Porto Alegre: Sergio Antonio Fabris, 1995.

A ciência jurídica e os seus dois maridos. In: WARAT, Luiz Alberto. Territórios desconhecidos: a procura surrealista pelos lugares do abandono do sentido e da reconstrução da subjetividade. Vol.1. Florianópolis: Fundação Boiteux, 2004.

Pálpitos epistemológicos para el siglo XXI. In: WARAT, Luiz Alberto. Epistemologia do Direito: o sonho acabou. Vol.2. Florianópolis: Fundação Boiteux, 2004.

WOLKMER, Antônio Carlos. Da crítica moderna eurocêntrica à crítica libertadora do Direito na América Latina. In: KROHLING, Aloísio (org.). História da Filosofia do Direito. Curitiba: Juruá, 2014. 